Cahiers $d u$ MONDE RUSSE

\section{Cahiers du monde russe}

Russie - Empire russe - Union soviétique et États indépendants

$49 / 4 \mid 2008$

Destins individuels et terreur. Jeunesse dans la société post-stalinienne

\title{
Jeff Sahadeo, Russian colonial society in Tashkent
}

\section{Isabelle Ohayon}

\section{(2) OpenEdition}

Journals

Édition électronique

URL : https://journals.openedition.org/monderusse/6991

DOI : 10.4000/monderusse. 6991

ISSN : $1777-5388$

Éditeur

Éditions de l'EHESS

Édition imprimée

Date de publication : 28 décembre 2008

Pagination : 812-815

ISBN : 978-2-7132-2197-2

ISSN : $1252-6576$

Référence électronique

Isabelle Ohayon, "Jeff Sahadeo, Russian colonial society in Tashkent ", Cahiers du monde russe [En ligne], 49/4 | 2008, mis en ligne le 24 décembre 2009, consulté le 02 septembre 2022. URL : http:// journals.openedition.org/monderusse/6991; DOI : https://doi.org/10.4000/monderusse.6991

Ce document a été généré automatiquement le 2 septembre 2022

Tous droits réservés 


\title{
Jeff Sahadeo, Russian colonial society in Tashkent
}

\author{
Isabelle Ohayon
}

\section{RÉFÉRENCE}

Jeff SAHADEO, Russian colonial society in Tashkent, 1865-1923. Indianapolis : Indiana

University Press, Bloomington, 2007, 317 p.

1 Faire une histoire du Tachkent colonial se justifiait plus que pour n'importe quelle ville d'Asie centrale impériale. Les steppes kazakhes, peuplées de nomades, n'avaient jamais, par définition, requis l'établissement d'une grande ville centrale pour consolider le pouvoir russe.Un système de fortifications et de postes avancés s'était avéré suffisant jusqu'à la création du fort de Vernyj (Alma-Ata) en 1854, qui s'affirmera bien plus tard comme l'un des centres du pouvoir colonial. Mais Tachkent ne répondait pas du tout au même schéma de colonisation, notamment parce que la ville ne se prêtait pas à la technique des cantonnements cosaques. "Asiatique » et musulmane, elle possédait une structure urbaine particulière, composée de quartiers fermés et emmurés, les mahalla, qui fonctionnaient selon des principes d'autonomie politique et économique. Pourtant, elle fut l'objet d'une conquête militaire singulièrement rapide puisque la prise de la ville fut expédiée en deux jours - contre deux mois pour celle d'Alger par les troupes françaises par exemple. Tachkent n'opposa qu'une faible résistance, même ultérieure, à la différence des expériences caucasienne ou algérienne là encore, qui donnèrent lieu à des combats sanglants et à une opposition organisée et durable. Tachkent occupait en effet une position paradoxale. La ville se trouvait à la jonction du monde des steppes, du khanat de Kokand, qui contrôlait toute la vallée du Ferghana, et des oasis de la vallée du Zeravchan de l'émirat de Boukhara (Samarkand, Boukhara) - et constituait le nœud régional de l'activité artisanale et commerciale. Mais, en même temps, elle souffrait ipso facto d'une évidente fragilité politique puisqu'elle était constamment disputée, depuis le début du 
$\mathrm{XIX}^{\mathrm{e}}$ siècle, entre les pouvoirs alentour qui se trouvaient quant à eux en marge des innovations militaires techniques et stratégiques.

La conquête de la ville en 1865, puis son annexion à la Russie en 1866, marque un tournant dans la politique impériale au Turkestan à différents titres. Elle coïncide avec les réformes qui reconfigurent profondément la structure administrative et le maillage des territoires des steppes et du Turkestan. Elle entérine en cela la colonisation comme le rattachement de nouveaux territoires et non plus comme un processus d'avancée vers les mers chaudes, tandis que la mise en œuvre d'un ambitieux projet urbanistique pour Tachkent s'inscrira pleinement dans le mouvement de modernisation initiée par les grandes réformes d'Alexandre II et signera l'avènement de la puissance impériale en Asie centrale. C'est cette histoire de la construction de la ville qui est l'objet de l'excellente monographie de Jeff Sahadeo, ainsi que la constitution, entre 1865 et 1923, d'une société coloniale complexe et disparate.

Dès 1866, la petite société russe de Tachkent, rassemblée derrière le gouverneur général Von Kaufman, était mue par une ambition civilisatrice et voulait faire de la ville un fleuron de la cité impériale moderne. La construction de larges artères, de places et de jardins planifiés sur le modèle de la référence européenne par excellence, SaintPétersbourg, devaient atténuer le caractère arriéré et préjugé insalubre de la ville musulmane. Le centre duTachkent russe se bâtit en effet en marge des vieux quartiers, de ses ruelles étroites et de ses maisons en terre battue, de l'autre côté du canal Ankhor qui marquait désormais une limite forte entre les deux mondes cloisonnés du Tachkent colonial. Professeurs, scientifiques, notables éclairés, tous s'impliquaient, par le biais de la presse, des cercles et des sociétés savantes, dans le débat sur la physionomie de la "ville du futur ». L'innovation architecturale chère aux colons n'était pourtant pas une fin en soi ; l'investissement de l'espace public récemment créé, par une multitude de cérémonies, parades et autres manifestations culturelles, constituait un élément fort de la sémiotique du pouvoir et de la promotion de la nouvelle identité de la ville (ch. 1).

Pourtant, quoique les notables autochtones très rapidement cooptés se soient affichés aux côtés des administrateurs coloniaux lors de ces démonstrations de puissance, le succès de cette entreprise était largement freiné par les contingences matérielles et par la sociologie des migrants de Russie installés dans la ville. D'une part, l'empire n'accordait pas suffisamment de fonds pour construire les quartiers et les ouvrages programmés, et, d'autre part, une population de soldats, de travailleurs déclassés, importaient quant à eux le revers de la « civilisation » européenne avec son chapelet de déviances: alcoolisme, prostitution, corruption, etc. Les autorités s'efforçaient de masquer ce phénomène qui nuisait à l'image d'oasis de progrès qu'elles entendaient refléter (ch. 2). Elles partageaient en cela la position de catégories engagées de la population, tels les ouvriers du chemin de fer qui, à l'avant-garde des mobilisations sociales, se considéraient comme les acteurs de la modernisation du Turkestan. Issus pourtant des classes paysannes attirées par les hauts salaires proposés pour construire la ligne Orenbourg-Tachkent, les cheminots venus de Russie, que le pouvoir impérial avait préférés à la main-d'œuvre locale, auraient ensuite un rôle contestataire de premier ordre pendant les révolutions de 1905 et 1917 à Tachkent, remettant notamment en cause les privilèges des notabilités coloniales (ch. 4). De même, de 1918 à 1923, avant que les bolcheviks ne soient en mesure d'asseoir leur contrôle sur la ville, les ouvriers maintinrent une forte pression politique en organisant de puissants comités de grève (ch. 7). 
Une série de stéréotypes sur l'arriération des Centrasiatiques présidait à la relation des autorités tsaristes avec la population, bien que le pouvoir ait rapidement été forcé de lui reconnaître un certain talent pour les activités marchandes. La tension latente entre colonisateurs et colonisés surgit au cours d'un épisode emblématique qui avait déjà fait l'objet d'un article remarqué de l'auteur dans Slavic Review ${ }^{1}$. L'épidémie de choléra qui s'abattit sur la ville en 1892 révéla les profondes divergences entre médecins européens et guérisseurs autochtones et, partant, la méconnaissance des pratiques et valeurs fondamentales de la société turkestanaise de la part des administrateurs russes. La mise en quarantaine des malades, l'autopsie et l'inhumation accélérée des victimes de l'épidémie dans un cimetière excentré, décidées en violation des croyances et des règles funéraires locales, provoquèrent une importante émeute qui fut réprimée dans le sang. Cette confrontation témoignait plus largement de la perception idéalisée et erronée que les autorités de la ville avaient d'une société centrasiatique qu'elles pensaient homogène et soumise, à l'image de ses représentants et médiateurs officiels, tel l'administrateur en chef de la ville asiatique, Muhammad Yaqub, qui fut d'ailleurs violemment pris à partie par les citoyens musulmans de Tachkent en 1892 (ch. 3).

6 La crise de l'été 1916, déclenchée par la conscription obligatoire des allogènes, décrétée par le tsar, finit d'affaiblir le régime colonial et d'entériner le divorce entre les représentants de l'empire et la société centrasiatique. La précipitation des événements jusqu'à la guerre civile fit entrer la ville dans une longue période de violence et de famine. Les clivages internes aux élites centrasiatiques locales, qui divisaient réformateurs djadids et oulémas conservateurs, se superposèrent aux nouveaux équilibres politiques d'après 1917. Alors que les sociaux-démocrates gagnèrent les élections à la douma de l'été 1917 et que la prise du pouvoir à Tachkent par les régiments bolcheviques s'accompagna de pillages et d'exécutions, parmi les autochtones ce furent les oulémas qui obtinrent la majorité des suffrages contre les djadids qui cherchèrent ensuite à constituer un gouvernement autonome dans la ville de Kokand dont ils prirent l'assaut en 1918. La répression par l'Armée rouge à laquelle aboutit leur tentative fut symptomatique de l'ambiguïté du statut des élites centrasiatiques aux yeux des Européens (ch. 8). Un certain maintien de la relation coloniale par les plus progressistes, durant la période chaotique de mise en place du régime soviétique à Tachkent, laissait présager de la complexité des rapports entre Centrasiatiques et Occidentaux dans les décennies suivantes.

7 L'ouvrage de Jeff Sahadeo, fondé sur les archives de la ville et de l'oblast' de Tachkent, sur les archives centrales d'Ouzbékistan, celles du GARF et du RGASPI, dessine avec finesse les contours de la société coloniale à Tachkent jusqu'aux prémices de la soviétisation, donnant ainsi à voir l'importance des configurations sociales qui préexistaient aux transformations soviétiques. Il montre la vulnérabilité d'une société coloniale imprégnée de racisme, en proie à de fortes tensions entre classes, entre groupes nationaux et entre sexes. La crise alimentaire consécutive à la Première Guerre mondiale avait par exemple projeté les femmes russes de basse extraction sur le devant de la scène quand elles prirent la tête de violentes émeutes contre les autorités impériales et contre les magasins et les marchands centrasiatiques (ch.6). La contestation du pouvoir impérial, qui émanait aussi bien des autochtones que des Russes, n'impliquait pourtant pas une solidarité politique des migrants avec les populations locales, de même qu'elle ne remettait pas en cause le primat du centre sur la périphérie, le centre semblant faire peu de cas de son administration et de sa population excentrées. À la fois conçu comme 
une colonie exploitée pour ses matières premières (en particulier le coton qui alimentait les usines textiles de Russie), et comme l'échiquier d'une rivalité avec l'Empire britannique, le Turkestan - tout comme sa capitale - demeuraient des confins militarisés et peu développés en dépit des ambitions d'une partie de l'élite russe locale. La monographie de Jeff Sahadeo fait la preuve de la grande pertinence de l'histoire sociale à l'échelle d'une ville pour éclairer les multiples contradictions de la politique de l'empire russe en Asie centrale. Elle s'impose comme une référence dans un champ d'études en expansion, notamment en ce qui concerne la relation qui lie le colonisateur au colonisé au Turkestan, à l'image des travaux récemment parus d'Alexander Morrison ${ }^{2}$ et de Paolo Sartori ${ }^{3}$.

\section{NOTES}

1. "Epidemic and Empire: Ethnicity, Class, and "Civilization" in the 1892 Tashkent Cholera Riot », Slavic Review, 64 (1), 2005, p. 117-139.

2. Alexander Morrison, Russian Rule in Samarkand 1868-1910: A Comparison with British India, New York : Oxford University Press, 2008, 400 p.

3. Paolo Sartori, "Judicial elections as a colonial reform. The Qadis and Biys in Tashkent, 1868-1883 », CMR, 49 (1), janv.-mars 2008, p. 79-100. 